\title{
Is there such a thing as a family constitution? A test based on credit rationing
}

\author{
Alessandro Cigno - Gianna C. Giannelli • \\ Furio C. Rosati · Daniela Vuri
}

Received: 29 April 2004 / Accepted: 20 April 2006

(C) Springer Science+Business Media, LLC 2006

\begin{abstract}
The paper tests the hypothesis that private transfers can be explained by the existence of self-enforcing family constitutions prescribing the minimum level at which a person in middle life should support her young children and elderly parents. The test is based on the effect of a binding credit ration on the probability of making a money transfer, which can be positive only in the presence of family constitutions. Allowing for the possible endogeneity of the credit ration, we find that rationing has a positive effect on the probability of giving money if the potential giver is under the age of retirement, but no significant effect if the person is already retired. This appears to reject the hypothesis that transfer behavior is the outcome of unfettered individual optimization on the part of either altruistic or exchange motivated agents, but not the one that individuals optimize subject to a self-enforcing family constitution. The policy implications are briefly discussed.
\end{abstract}

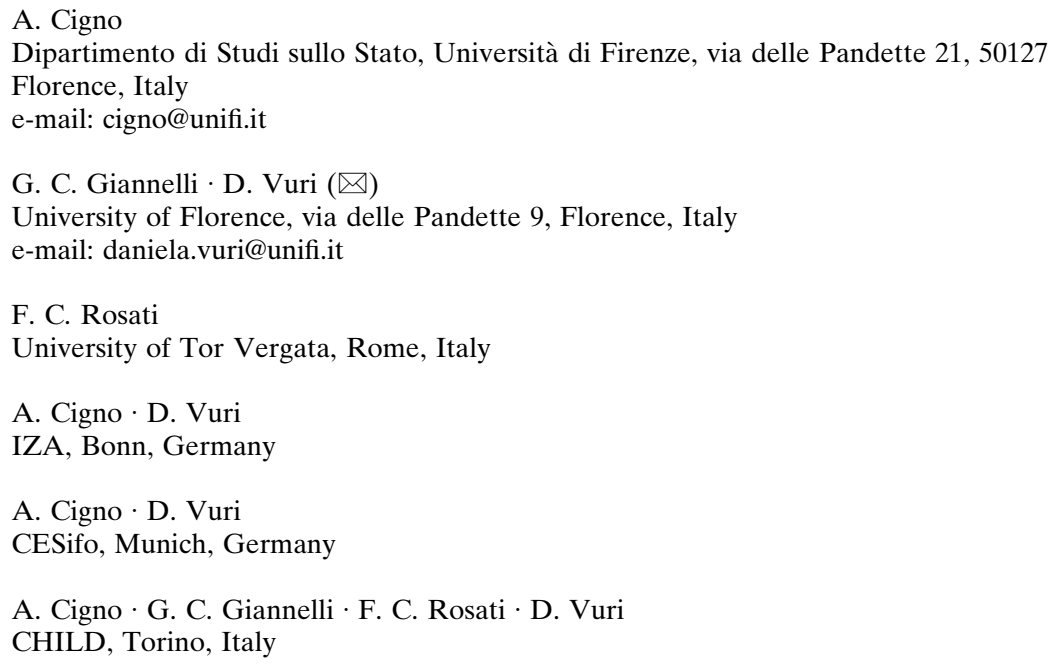


Keywords Family constitution $\cdot$ Altruism $\cdot$ Exchange $\cdot$ Credit ration . Private transfers $\cdot$ Personal services

JEL Classifications $\quad \mathrm{D} 13 \cdot \mathrm{J} 13 \cdot \mathrm{J} 14$

\section{Introduction}

Parental transfers in the form of personal care and direct expenditure are clearly crucial for the well-being of the very young. In different forms, parental transfers are important also for the well-being of young adults, who would otherwise find it difficult to finance human capital investment. Transfers in the opposite direction are important too. In countries with underdeveloped financial markets, or where personal safety is not sufficiently guaranteed by the state, the old would find it difficult to survive without the material support and personal protection of grown-up children. Such considerations are less relevant in developed countries, where personal safety is less of a problem, and the old tend to be relatively well provided with cash through state pensions and personal savings. In those countries, however, the personal attention of grown-up children is even more of a scarce good than in less developed countries, and thus highly valued by the old.

There is evidence that intergenerational intra-family transfers of money and other tangible assets are substantial not only in developing countries, ${ }^{1}$ but also in highly developed ones. For example, the 1968-88 waves of the Panel Study of Income Dynamics conducted by the Institute for Social Research of the University of Michigan report that $24 \%$ of US children receive money from their parents. Indeed, Greenwood and Wolff (1992) calculate that, between 1962 and 1983, more than half the wealth of Americans aged 40-49, and as much as $85 \%$ of the wealth of those aged less than 40 , came from inter-vivos transfers. A similar picture emerges from the 1992 Enquete Trois Générations conducted in France by Caisse Nationale d'Assurance Vieillesse (AttiasDonfut \& Wolff, 2000), and from the first wave of the Indagine Multiscopo conducted in Italy around 1991 by Istituto Nazionale di Statistica (ISTAT, 1993). ${ }^{2}$ Transfers of personal services are also commonplace and, unlike money transfers, go in both directions, from children to parents as well as from parents to children. The already mentioned University of Michigan study reveals that more than $27 \%$ of US children give personal services to, and more than $30 \%$ receive personal services from their parents. Broadly the same message is conveyed by the same institution's Health and Retirement Study, focussed on the old, and from the French and Italian surveys already mentioned.

\footnotetext{
${ }^{1}$ See, for example, Bhaumik and Nugent (2000), or Foster and Rosenzweig (2000).

2 The results of the second wave were only just becoming available at the time of writing.
} 
In the economic literature, these transfers tend to be modelled either as altruistic gifts yielding direct utility for the giver as well as for the receiver, the so-called altruistic model (Becker, 1974), or as payment for services rendered, the so-called exchange model (Cox, 1987; Cox \& Rank, 1992). ${ }^{3}$ In either case, the model assumes individual optimization subject only to the law of the land. By contrast, sociologists tend to explain human actions in general, and domestic behavior in particular, as socially determined (Finch, 1989). Cigno (1993, 2006) throws a bridge across the economicssociology divide by modelling the extended family as a group of individuals who find it in their interest to abide by a set of fundamental rules, a "family constitution". According to this approach, agents choose first whether or not to comply with the constitution. If they decide to comply, they then optimize subject to the constitution. Otherwise, they optimize subject only to the law of the land, as in more conventional economic models. A constitution is said to be self-enforcing if it is in the agent's interest to comply with it.

Understanding how transfers are determined is important for a number of reasons, including that it tells us how those transfers would be affected by public intervention. If they are genuine gifts, private transfers will in fact tend to offset public ones, and thus to reduce the redistributive power of the latter (Cox \& Jakubson, 1995). If they constitute payment by the relatively rich for services received from the relatively poor, they will still affect the government's ability to reduce income inequality, but not its ability to reduce utility inequality. If they reflect family rules, by contrast, voluntary transfers will be affected only by policies that alter the relative pay-off of obeying or not obeying those rules. The introduction of a mandatory pension scheme, for example, reduces the proportion of the active population who subscribe to a family constitution because it lowers the demand for old-age support (Cigno \& Rosati, 1996).

Although the issue is of some importance, there have not been many attempts at discriminating empirically among all three possible explanations of transfer behavior. To the best of our knowledge, micro-econometric investigations have so far limited themselves to testing altruistic against exchange motives, and the results do not appear to come down firmly in favor of one or the other of the two hypotheses (Cox \& Rank, 1992). The only tests of the constitution hypothesis carried out so far are based on aggregate time series (Cigno \& Rosati, 1996; Cigno, Casolaro, \& Rosati, 2003). These tests appear to reject the hypothesis that household saving and fertility behavior is the outcome of unfettered individual optimization, but not the one that this is the outcome of individual optimization subject to a family constitution. In the present paper, we use Italian survey data to discriminate empirically between the hypothesis that voluntary money

\footnotetext{
${ }^{3}$ There is also a number of half-way houses, for example the model where parents can manipulate their children's preferences (make children altruistic towards their parents) by bearing certain costs; see, for example, Stark (1995), Guttman (2001).
} 
transfers can be explained by the existence of self-enforcing family constitutions, and the alternative that such transfers are either genuine gifts or straight payment for services received.

To that end, we identify a circumstance in which an agent will behave differently according to whether he does or does not face a self-enforcing family constitution. The circumstance is the presence of a binding credit ration. In Sect. 2, we argue that credit rationing cannot increase the probability of making monetary transfers if individual decisions, altruistic or otherwise, are not restricted by the existence of a family constitution. It may, by contrast, if credit rationing raises the probability that a family constitution is self-enforcing. In other words, credit rationing may increase the probability of making monetary transfers if the agent has the option of switching from a purely individualistic strategy, to one that entails obligations towards other family members. The reason is simply that, in order to be enforceable, a family constitution must offer those who submit to its discipline a marginal return to money spent on children that exceeds the market interest factor. Other things being equal, the shadow-price of the credit ration is thus lower if the agent complies with a family constitution, than if he does not. We also argue that credit rationing increases the probability that a person will receive monetary transfers in all the models considered.

Were we to observe that a person with given assets, income and other characteristics is more likely to receive money transfers if she is credit-rationed, that would not tell us anything about the model that generated the data. Were we to observe, by contrast, that a person with given characteristics is more likely to make money transfers if she is credit-rationed, that would lead us to reject the hypothesis that these transfers are either gifts, or straight payment for services received. If the person were in middle life, and had children, the finding would be consistent with the hypothesis that she is complying with a family constitution. In Sect. 3, we construct a test of this hypothesis based on the effect of credit rationing on the probability of making a money transfer.

The data come from a Bank of Italy survey that conveys information on whether an agent is credit-rationed, and makes money transfers. This particular version of the survey is unique in that all previous and subsequent ones solely ask whether the agent receives money transfers, and cannot thus be used to discriminate empirically among the different hypotheses under consideration. Similar surveys, for example ISTAT's Indagine Multiscopo, typically provide only one of the two pieces of information required for the test. Allowing for possible endogeneity of the credit ration, we find that rationing has a significantly positive effect on the probability of making monetary transfers if the potential giver is still active in the labor force, but not if he is retired. That is consistent with the hypothesis that the individuals making these transfers are constrained by a family constitution, and rejects the alternatives under consideration. 


\section{A sketch of the theory}

The properties of the altruistic and exchange models are too well known to require anything more than a brief outline. Altruism is generally taken to mean that a person derives direct utility from the utility of others (Becker, 1974). Assuming that the latter is a normal good, altruism then implies that the probability of a money transfer is an increasing function of the giver's, and a decreasing function of the receiver's wealth. ${ }^{4}$ This prediction continues to be valid, indeed it is reinforced, if the market does not offer perfect substitutes for the personal services of close relatives. ${ }^{5}$ Optimization does in fact entail that the beneficiary will get the combination of money and personal services that allows him to achieve any given level of utility at the lowest possible cost to the giver. A middle-age person will then give mostly money if she is wealthy, and mostly personal services if she is poor. Conversely, an old person will get more personal services if she is relatively well provided with money, and more cash if she is short of it. A young adult will get mostly money.

Much the same is true if money transfers are not gifts, but payment for services rendered (Cox, 1987; Cox \& Rank, 1992). The highest price that a person is willing to pay for a service does in fact increase with her wealth. Similarly, the lowest price that a person is willing to accept in order to perform a service increases with her wealth. Like the altruistic model, the exchange model thus predicts that the probability of a money transfer is an increasing function of the giver's, and a decreasing function of the receiver's wealth. Since credit rationing reduces lifetime wealth, a further implication of both models is that a person with given assets, income, etc. is less likely to make a money transfer if she faces a binding ration, than if she does not.

The constitution hypothesis requires a somewhat lengthier exposition. ${ }^{6}$ If a transfer is made in the expectation of some kind of return, the person making it must be reasonably confident that the other party will deliver his side of the deal. That is not a problem if the exchange is simultaneous ("if you visit Grandma, she will make you a present"), or occurs on a regular basis ("I shall give you a dollar every time you sweep the yard"). It is a problem, however, if the deal is that a middle-age person will give money or personal services to a young one in exchange for money or personal services 20 years on, when the latter reaches middle life, and the former is old. Such a deal could well be mutually advantageous, either because the young have difficulty in borrowing money from the capital market, or because the personal services envisaged by

\footnotetext{
${ }^{4}$ Under the strong assumption of income pooling, the two marginal effects should add up to unity. No empirical study has ever found that (see, for example, Altonji, Hayashi, \& Kotlikoff, 1995).

${ }^{5}$ If it did, there would be no point in distinguishing between goods that money can buy, and personal services supplied by a family member. An elderly person who regards the services of a paid nurse as a perfect substitute for those of a grown-up daughter is in fact indifferent between receiving an hour of her daughter's time, or a sum of money sufficient to hire a nurse for an hour.

${ }^{6}$ For a full exposition, see Cigno (2006).
} 
the deal have no perfect market substitutes, but it would not come off in the absence of an enforcement mechanism.

The mechanism suggested by Cigno (1993) for overcoming this insufficient commitment problem is a "family constitution", 7 a set of unwritten, typically unspoken, rules prescribing the amount of money that a middle-age person must give each of her young children, and each of her elderly parents. Compliance is ensured by a clause, embedded in the constitution, that excuses an agent from giving anything to an elderly parent who, in his time, disobeyed the rules. This clause dangles the threat of receiving no old-age support from her children over the head of any person who might contemplate giving less than the constitution prescribes to either a young child, or an elderly parent (who, in his time, obeyed the rules). The existence of such a constitution confronts the agent with a choice of two strategies. One, called "go it alone", consists of ignoring the constitution, and providing for old age by saving. The other, called "comply", consists of acquiring credits towards his children by obeying the constitution. A constitution is self-enforcing if the set of comply strategies is a sub-game perfect Nash-equilibrium. The necessary and sufficient condition for this to be the case is that the pay-off of going it alone is no higher than the pay-off of complying. In the Nash equilibrium, the characteristics of the family constitution are determined by the personal characteristics of those who find it advantageous to comply with it.

The marginal return to the money that a person sets aside for old age is equal to the market interest factor, $r$, if she is a go-it-aloner and to the ratio between money received from and given to (or directly spent on) children, $r^{*}$, if she is a complier. Since complying has a fixed cost, represented by the amount that the agent must pay her own parents, ${ }^{8}$ a necessary condition for the pay-off of complying to be no lower than the pay-off of going it alone is that $r^{*}$ is strictly greater than $r$. Otherwise, there would be no way that a complier could recover the fixed cost. In the absence of risk, compliers will then save nothing. That is not necessarily true, however, in the presence of risk. If the risk of investing in children is not positively correlated with that of investing in conventional assets, a risk-averse complier may well find it optimal to do some precautionary saving (Rosati, 1996).

The basic model does not consider the possibility that a constitution might allow the agents to give personal services instead of money. Cigno and Rosati (2000) allow for it by re-wording the constitution so that an agent is required to give each of her young children, and elderly parents money and personal services yielding at least the same utility as a specified sum of money. As it allows the agent to choose the least-cost mix of money and personal services with which to satisfy the constitution, and given that the money equivalent of

\footnotetext{
${ }^{7}$ According to the economic theory of constitutions (Buchanan, 1987), it may be in the interest of a group of agents to first agree on certain basic rules, that will permit them to safely renounce the dominant strategy in a prisoner's dilemma type of situation, and then optimize subject to those rules.

${ }^{8}$ This cost is fixed in the usual sense that it does not depend on the level of activity, in this case on the number children, and thus on how much the agent will receive from them in old age.
} 
the utility of receiving personal services without a perfect market substitute can be much higher than the market value of the time and effort necessary to provide those services, this extension of the basic model reduces the fixed cost, and raises the marginal return of complying. It thus raises the probability that self-enforcing family constitutions exist.

In the basic model agents are assumed to be self-interested. Cigno (2006) shows that introducing descending altruism in the constitution model does not change its predictions in any matter of substance, unless the agent is so rich and altruistic that the constitution does not impose any effective constraint on his behavior. In that extreme case, the constitution is obviously irrelevant. In every other case, the only difference altruism makes is that the old may now give money to their grown-up children (either directly or indirectly by subsidizing the grandchildren). That is all the more likely if what the parents get from their grown-up children is personal services without a perfect market substitute, in which case they would in effect be returning in the form of cash, and for purely altruistic reasons, part of the money equivalent of the personal services that they are receiving. ${ }^{9}$

Some of the behavioral implications of the constitution story are no different from those of the other two models. A person is likely to give mostly money if her wealth is high, mostly personal services if it is low. Conversely, she is likely to receive mostly money if her wealth is low, mostly personal services if her wealth is high. ${ }^{10}$ Therefore, observing how money transfers vary in relation to the giver's and the receiver's assets and income does not allow us to discriminate among the three models. The same is true if we observe how the probability of receiving a money transfer is affected by a binding credit ration. As rationing reduces lifetime wealth, all the models considered predict that rationing raises the probability of receiving a money transfer.

Other predictions of the constitution story differ sharply from those of the other two models. Suppose, for example, that the government were to introduce or expand an actuarially fair pension system. ${ }^{11}$ Altruistic and exchange models predict that such a policy would not affect transfer behavior, ${ }^{12}$ because it would not alter the agent's lifetime wealth. The constitution model, by contrast, predicts that transfer behavior may be affected. If a sufficiently large part of an agent's demand for old-age consumption is taken care of by the pension, and given that the agent can avoid participating in the family scheme, but not in the pension system, a number of people who would have otherwise complied with their respective family constitutions will then go it alone. Put

\footnotetext{
${ }^{9}$ That, notice, is not the same as actually paying for those services as in the exchange model. In the constitution model, the old have already paid for what they are getting, and any money they might give their grown-up children will be a gift.

${ }^{10}$ Cigno and Rosati (2000), and Sloan and Zhang (2002) find precisely that.

${ }^{11}$ A system is said to be actuarially fair if the expected value of the benefits at the time of retirement equals the capitalized value of the contributions made. Therefore, an actuarially fair scheme does not alter the wealth position of those who participate in it.

${ }^{12}$ Except for the distortion of marginal incentives if pension contributions increase with labor.
} 
another way, a number of family constitutions will cease to be self-enforcing. Transfers will consequently fall. Another important difference between the family constitution and the other two hypotheses has to do with the effect of credit rationing on the probability of making a monetary transfer.

We have already noted that both the altruistic and the exchange model predict a negative effect of credit rationing on the probability of giving money. That is not necessarily true in the constitution story. Suppose, for example, that the market rate of interest is $3 \%$. Suppose also that, by obeying his family constitution, an agent could qualify for a $10 \%$ return, in money or personal services, on money and services devoted to his young children. Were he allowed to borrow from the market and invest in his children, the agent would obviously do so. But an entitlement arising from an informal family arrangement cannot be ceded to a third party as if it were a commercial asset, and cannot thus be used as collateral to obtain credit. ${ }^{13}$ A complier's ability to borrow from the capital market will thus depend on factors other than his domestic entitlements.

Let us then suppose that, given the market rate of interest, the agent maximizes his utility if he borrows the amount $-S$ from the market, and gives nothing to his parents and children. Were he allowed to borrow that amount, the agent would go it alone. If his credit ration is sufficiently smaller than $S$, however, he may be better-off complying. The imposition of a binding ration could thus induce an agent who would otherwise not give anything to anybody, to start making monetary and non-monetary transfers to his elderly parents and young children.

The argument can be illustrated with the help of Fig. 1. $C_{1}$ denotes current consumption, $C_{2}$ future consumption, $D$ current transfers to young children, and $T$ current transfers to elderly parents. The agent has current income $Y$, future income $P,{ }^{14}$ and credit ration $B$. If he decides to go it alone, the relevant budget constraint is represented by the straight line through point $a$, with slope equal to the market interest factor, $r$. If he decides to comply, the relevant budget line is the one through point $b$, with slope equal to the marginal return implicitly offered by the family constitution, $r^{*}$. The budget set is thus delimited by the broken line through points $b, c$ and $d$. If $B$ is at least equal to $-S$, the agent will go it alone. The optimum is then at point $d$, where the agent saves the negative amount $S(-B<S<0)$, and makes no transfers. His future consumption is equal to $P+S r<P$. But suppose that $B$ is smaller than $-S$, say zero. The agent will then comply, and thus make transfers. The optimum is in that case at point $b$, where current consumption is equal to $Y-D-T$, and future consumption to $P+D r^{*}>P$.

\footnotetext{
${ }^{13}$ Indeed, if it were at least in part an entitlement to receive personal services without perfect market substitutes from a grown-up child, that could well be of great value to the child's parent, but of little use to a third party such as a bank.

${ }^{14}$ If the agent can comply with the constitution by supplying personal services without a perfect market substitute instead of money, income is to be interpreted as full income, and transfers as the money equivalent of the utility of the person receiving the transfer.
} 
Fig. 1 Effects of creditrationing

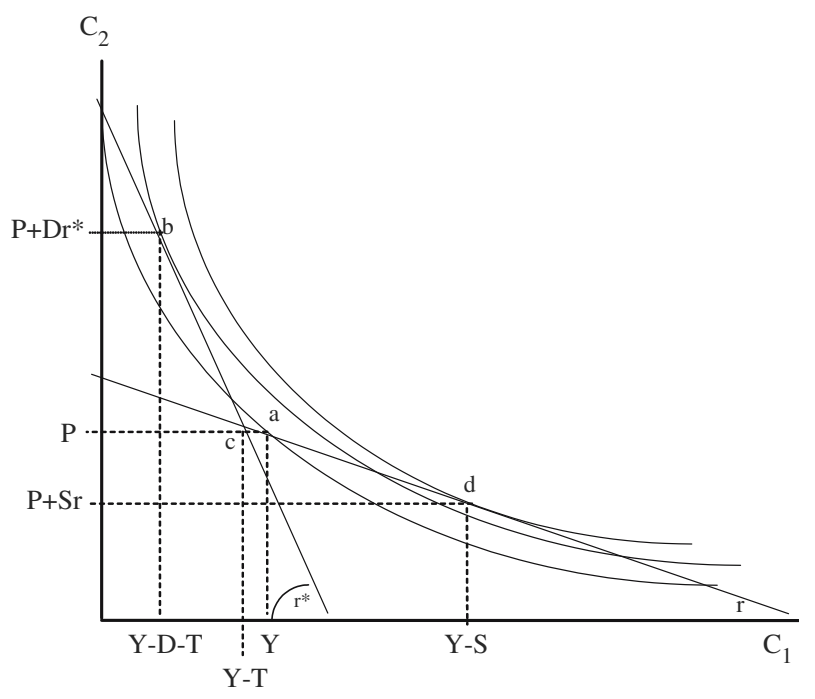

One way to summarize this is to say that complying reduces the shadowprice of the credit ration. If it reduces it sufficiently, tighter credit will induce the agent to switch from the go-it-alone to the comply strategy. Therefore, according to the constitution model, credit rationing raises the probability that a person in middle life will make a monetary transfer. Since the altruistic and exchange models predict the opposite, we can then use data on credit rationing and transfers made to test the hypothesis that self-enforcing family constitutions exist. We cannot use information on transfers received, because all the models considered predict that a person is more likely to receive cash if she is credit-rationed, than if she is not.

\section{Empirical evidence}

What we need to show, if we want to discriminate empirically between the constitution story and the two alternatives, is then that observed behavior is consistent with optimization in the domain restricted by the presence of a family constitution, but not with optimization in the domain restricted by its absence. We have identified two possible areas where the behavioral implications of the constitution model differ from those of altruistic and exchange models. One has to do with the effects of pension policy, the other with those of credit rationing. Aggregate time-series evidence regarding the effects of pension policy on saving and fertility behavior in Germany, Italy, Japan, the UK and the USA appears to reject the alternatives to the constitution hypothesis. ${ }^{15}$ In what follows, we use Italian survey data to analyze the effects of credit rationing on the probability of making money transfers.

15 See Cigno and Rosati (1992, 1996, 1997), and Cigno et al. (2003). 
The Bank of Italy biannual household surveys (SHIW) give information on household composition, income, assets, and access to credit. Normally, they also provide information on money transfers received from non-coresident "friends or relatives". As already pointed out, the latter is of no use for discriminating between the constitutional hypothesis and the two alternatives under consideration. Exceptionally, however, the 1991 edition provides information on money transfers made. ${ }^{16}$ This gives us the opportunity to test the hypothesis that transfer behavior is constrained by self-enforcing family constitutions. The survey in question does not provide information on personal services.

The latter is provided by ISTAT's almost contemporaneous Indagine Multiscopo, which however is silent on the subject of access to credit. ${ }^{17} \mathrm{We}$ shall then use this second survey for descriptive purposes only, in order to supplement the information provided by the Bank of Italy. Figure 2 shows the age distribution of help given and received in the Multiscopo. It transpires from this diagram that a person in middle life is most likely to give some form of help and most likely to receive it in her youth or old age. Figures 3 and 4 show the age distribution of help given and received separately for moneyintensive and time-intensive forms of help. ${ }^{18}$ While confirming the life-cycle pattern of Fig. 2, these two diagrams add the important detail that money goes mostly to the young and personal services mostly to the old. The percentages are low because they refer to transfers between households. Were we to add transfers within households, we would likely get orders of magnitude similar to those reported for other countries.

Let us now go back to the Bank of Italy survey. This covers 24,930 individuals living in 8,188 households. It provides information on the household as a whole and on its individual members. Individual information includes age, sex, relationship to the household head (child, wife, parent, etc.), education, labor market status by professional level and sector of activity, income by source, and assets (which may include whole businesses, real estate, jewelry and other durables, as well as net financial assets) of each resident household member. It also gives information on the number and ages (but not income or assets) of non-coresident parents and children of household members. Household-level information includes also the place of residence. Deleting some observations due to missing information, and excluding childless households (who obviously do not make transfers in order to secure filial

\footnotetext{
${ }_{16}$ Incidentally, this asymmetry prevented us from exploiting the small panel element contained in this series of surveys.

${ }^{17}$ Furthermore, it does not provide information on assets, and gives income information only in categorical form.

18 The questionnaire asks about a list of different forms of help given or received, including "economic help", "help with health matters", "help with domestic chores", "help with bureaucratic matters", and so on. We are classifying as money intensive not only what the questionnaire calls "economic help", but also "help with health matters", because that involves direct expenditure on medicines, private nurses, and the like. We classify everything else as time intensive.
} 


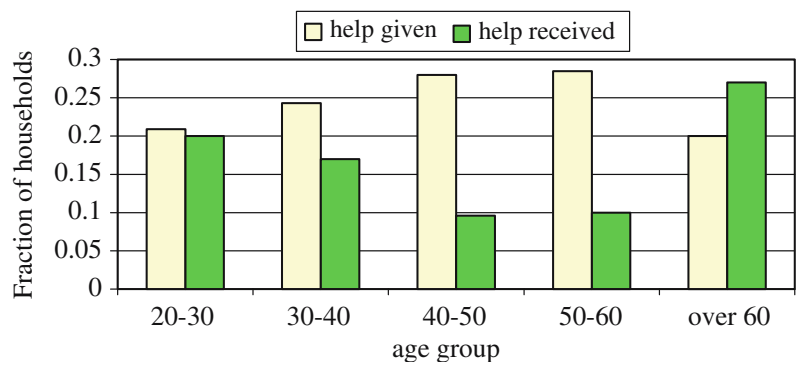

Fig. 2 Help given/received by age group. Source: Indagine Multiscopo 1991

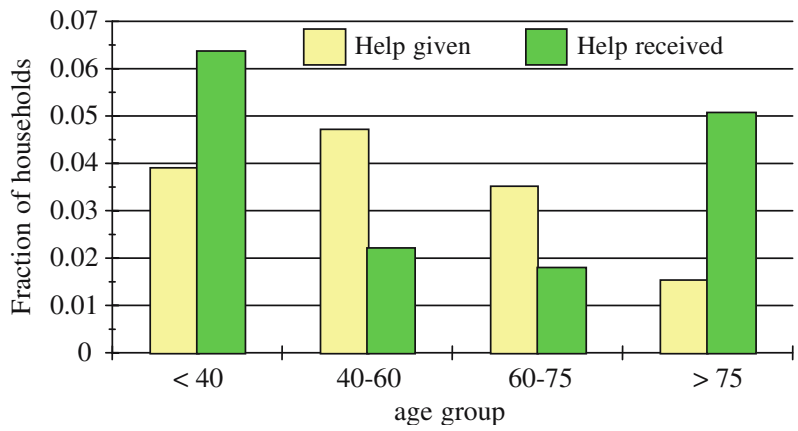

Fig. 3 Monetary transfers. Source: Indagine Multiscopo 1991

support) reduces the sample to 6,744 households. Descriptive statistics for the whole sample and for two sub-samples, one containing only households with head still working and the other containing only households with head already retired, are reported in Table 1.

One of the questions asked in the Bank of Italy survey is about monetary help in excess of 500,000 liras (around 350 euros at today's prices) given by any household member to non-coresident "friends or relatives" in the course of the interview year. ${ }^{19}$ While only affecting a minority (17\%) of households, such transfers are quite substantial (on average, $7.1 \%$ of the giver's disposable income) where they do occur. This percentage looks much higher than the one emerging from the Multiscopo (see Fig. 3). As already mentioned, however, that survey refers to transfers made by an individual, while the Bank of Italy survey refers to transfers made by any member of a household. As there are, on average, more than three persons per household, the two sets of figures are perfectly consistent. As neither survey provides information on the identity or characteristics of the beneficiary, these will have to be inferred. Altonji, Hayashi, and Kotlikoff (2000) show that when parents provide information on transfers made without identifying the relationship with the recipients, there is likely to be underreporting of the incidence of these transfers. This

19 Alimony to a former spouse, and mandated support for children living with a former spouse, are explicitly excluded. 
Fig. 4 Transfers of personal services. Source: Indagine Multiscopo 1991

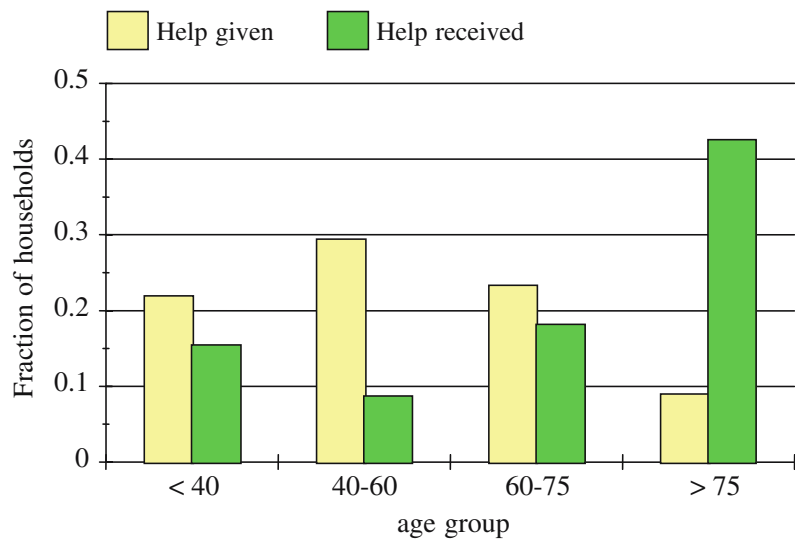

Table 1 Descriptive statistics

\begin{tabular}{|c|c|c|c|c|c|c|}
\hline \multirow[t]{2}{*}{ Variable } & \multicolumn{2}{|c|}{$\begin{array}{l}\text { All households } \\
\text { with children }\end{array}$} & \multicolumn{2}{|c|}{ Head working } & \multicolumn{2}{|c|}{ Head retired } \\
\hline & Mean & Std.dev. & Mean & Std.dev. & Mean & Std.dev. \\
\hline Transfers made & 0.17 & 0.37 & 0.17 & 0.37 & 0.16 & 0.37 \\
\hline Value of transfers (million liras) ${ }^{\mathrm{a}}$ & 2,17 & 3,13 & 1,99 & 3,2 & 2,58 & 3,49 \\
\hline Credit is rationed & 0.04 & 0.20 & 0.05 & 0.22 & 0.02 & 0.13 \\
\hline Liquidity ratio & 68.7 & 33.1 & 71.2 & 35.0 & 63.1 & 37.8 \\
\hline Income (million liras) & 31,2 & 18,8 & 33,5 & 19,0 & 26,1 & 16,1 \\
\hline Assets (million liras) & 170 & 269 & 178 & 264 & 151 & 279 \\
\hline Received assets & 0.22 & 0.42 & 0.23 & 0.42 & 0.21 & 0.41 \\
\hline No. of children at home & 1.40 & 1.10 & 1.69 & 1.01 & 0.76 & 0.99 \\
\hline No. of children $\leq 30$ away & 0.22 & 0.57 & 0.19 & 0.54 & 0.27 & 0.63 \\
\hline No. of children $>30$ away & 0.64 & 1.19 & 0.29 & 0.89 & 1.42 & 1.39 \\
\hline No. of parents $\leq 60$ away & 0.10 & 0.38 & 0.15 & 0.45 & - & - \\
\hline No. of parents $>60$ away & 0.55 & 0.74 & 0.74 & 0.78 & 0.14 & 0.39 \\
\hline No. of parents at home & 0.02 & 0.14 & 0.02 & 0.15 & 0.01 & 0.11 \\
\hline Head is male & 0.85 & 0.36 & 0.85 & 0.35 & 0.83 & 0.37 \\
\hline Age of head & 53.85 & 14.23 & 47.69 & 11.8 & 67.4 & 8.65 \\
\hline Head's education (years) & 8.11 & 4.25 & 8.84 & 4.26 & 6.51 & 3.79 \\
\hline Head worked in agriculture & 0.09 & 0.29 & 0.06 & 0.22 & 0.19 & 0.39 \\
\hline Head worked in industry & 0.33 & 0.47 & 0.31 & 0.46 & 0.37 & 0.48 \\
\hline Head worked in public sector & 0.27 & 0.44 & 0.26 & 0.44 & 0.26 & 0.42 \\
\hline Head worked in service sector & 0.31 & 0.46 & 0.37 & 0.48 & 0.18 & 0.38 \\
\hline Home is owned & 0.62 & 0.48 & 0.60 & 0.49 & 0.67 & 0.47 \\
\hline Resident in North West & 0.21 & 0.41 & 0.21 & 0.41 & 0.22 & 0.41 \\
\hline Resident in North East & 0.18 & 0.38 & 0.17 & 0.38 & 0.20 & 0.40 \\
\hline Resident in Centre & 0.21 & 0.40 & 0.20 & 0.40 & 0.23 & 0.42 \\
\hline Resident in South & 0.40 & 0.49 & 0.42 & 0.49 & 0.35 & 0.49 \\
\hline No. of observations & \multicolumn{2}{|c|}{6744} & \multicolumn{2}{|c|}{4633} & \multicolumn{2}{|c|}{2111} \\
\hline
\end{tabular}

a Only for households that make transfers

Source: Bank of Italy household survey (SHIW) 1991

Note: the sector of activity for the head of household already retired refers to the last job's sector before retiring 
measurement error could bias our results, but there is no way of saying by how much.

Another set of questions asks whether, in the interview year, any household member was denied credit by a financial institution or refrained from applying in the belief that it would be denied. ${ }^{20} \mathrm{We}$ shall consider credit-rationed any household whose members answered yes to either of those questions, but we have checked that nothing of substance changes if we consider rationed only those who answered yes to the first one. Although only $6.1 \%$ of those who made transfers were credit-rationed, as many as $25 \%$ of rationed households (as against $17 \%$ of the total) made transfers. ${ }^{21}$ We can thus see from the crude data that rationed households are more likely to make transfers. Since we are not told which household member (the head, the head's partner, or any adult coresident) is rationed, that also will have to be inferred.

\subsection{Probability of being rationed and probability of making a money transfer}

Since both the altruistic and the straight exchange model predict that credit rationing reduces the probability that a person of any age makes a money transfer, finding that this effect is positive would reject both models. By contrast, the constitutional model predicts that credit rationing may induce a middle-age person to switch from the go-it-alone to the comply strategy. Therefore, finding that rationing increases the probability that a person still in the labor force makes monetary transfers would not reject the constitutional model. The model would be rejected if rationing had this effect on retired persons. Merely finding that some retired people make money transfers would not reject any of the hypotheses considered. In particular, it would not reject the constitution hypothesis, because a complier may well make gifts when he gets old. We shall thus consider households with head still in the labor force separately from households with head already retired.

For each sub-sample and for the whole sample of households with children, we first estimate a probit model of the probability of making a money transfer taking credit rationing as exogenous and using the variables listed in Table 1 as controls. We find that being rationed increases the probability of making money transfers by $7.9 \%$ (with a $t$-statistics of 3.83 ) in the full sample, by 8.1 ( $t$-stat. 3.6) in the sub-sample with heads in the labor force, and by 7.6 ( $t$-stat. 1.36) in the one with retired heads. These are marginal effects (the full set of

\footnotetext{
20 The actual questions are: "In the course of 1991, did you or any other member of your household have a loan application rejected or curtailed by a bank or other financial institution?" and "In the course of 1991, did you or any other member of your household consider applying to a bank or other financial institution for a loan, but desisted thinking that the application would be rejected?"'.

21 On average, rationed households transfer more than the rest (449,000 liras, as against 360,500 for the whole sample). If we exclude households not making transfers, however, the mean is lower for rationed households $(1,821,000$ liras) than in the sample as a whole $(2,170,000$ liras $)$.
} 
estimates is available on request). These results are consistent with the family constitution hypothesis in that they show that households with head still working are significantly more likely to make monetary transfers if they are credit-rationed, while households with head retired are not significantly affected by credit conditions. Since a binding credit ration is partly the result of choice (if one does not wish to borrow, one cannot be rationed), however, there could be an endogeneity problem, and the estimates could thus be biased. To deal with that, we use an instrumental-variable approach. To identify the auxiliary equation for the probability of being rationed, we use dummies for home ownership and area of residence.

The justification for using home ownership is that real estate is less risky than other assets, and thus most acceptable as collateral by lending institutions. To this it could be objected that, when the household's net worth is controlled for, home ownership is an indicator of portfolio composition. Since homes are less liquid than other assets, home ownership could then have an independent portfolio-composition effect on transfer behavior. For this reason, we use the share of liquid assets to control for portfolio composition (calculated as the fraction of financial assets held in the form of cash and current bank or post office accounts).

The justification for using the area of residence as an identifying variable is that, for historical and structural reasons, credit is notoriously more difficult to obtain, and more expensive, in the southern than in the northern regions of Italy. To this it could be objected that geography may act as a proxy for cultural factors, and that it could thus have an independent effect on transfer behavior. This objection would have some force if we were talking of region of birth (not available in the data), rather than residence. During the 1950s and early 1960s, there was in fact massive migration from the South to the North of Italy, and the phenomenon persists on a smaller scale today. Even if it were true that family ties are stronger in southern than in northern culture, we would then have to assume that people change culture very quickly indeed as they migrate from South to North in order to be able to argue that the place of residence has a direct effect on the probability of making a transfer, independent of credit availability. ${ }^{22}$

The results of the first and second stage estimations are reported separately in Tables 2 and 3. The estimations were carried out simultaneously by the maximum likelihood method to take account of the binary nature of the rationing and transfer variables. Table 2 shows that, in the two sub-samples as in the full sample, the probability of being credit-rationed is lower for home owners, and decreases as the place of residence moves from South (the reference area) to North. The other first-stage regressors are:

\footnotetext{
${ }^{22}$ We checked for weakness of the instruments by regressing the rationing variable on the full set of explanatory and instrumental variables, as shown in Table 2, and testing whether the inclusion of the latter could be rejected by an $F$ test. As the $F$ statistics are well above the threshold value of 10 indicated in Bound, Jaeger and Baker (1995), we conclude that our instruments are not weak in a statistical sense.
} 
Table 2 First stage regressions: probit for being rationed

\begin{tabular}{|c|c|c|c|c|c|c|}
\hline \multirow[t]{2}{*}{ Variable } & \multicolumn{2}{|c|}{$\begin{array}{l}\text { All households } \\
\text { with children }\end{array}$} & \multicolumn{2}{|c|}{ Head working } & \multicolumn{2}{|c|}{ Head retired } \\
\hline & Coeff & $t$-stat & Coeff & $t$-stat & Coeff & $t$-stat \\
\hline Liquidity ratio & 0.002 & 2.53 & 0.003 & 2.88 & -0.0004 & -0.20 \\
\hline Income (million liras) ${ }^{\mathrm{a}}$ & 0.598 & 3.78 & 0.500 & 2.89 & 0.107 & 2.20 \\
\hline Assets (million liras) ${ }^{\mathrm{a}}$ & -0.010 & -0.73 & -0.011 & -0.68 & -0.014 & -0.47 \\
\hline Received assets & 0.215 & 3.05 & 0.232 & 3.01 & 0.167 & 0.95 \\
\hline No. of children at home & 0.089 & 2.97 & 0.048 & 1.41 & 0.161 & 2.26 \\
\hline No. of children $\leq 30$ away & 0.033 & 0.66 & 0.057 & 1.00 & -0.103 & -0.81 \\
\hline No. of children > 30 away & -0.011 & -0.26 & -0.049 & 0.78 & 0.038 & 0.60 \\
\hline No. of parents $\leq 60$ away & 0.018 & 0.23 & 0.028 & 0.36 & - & - \\
\hline No. of parents $>60$ away & -0.024 & -0.52 & -0.021 & -0.44 & -0.066 & -0.36 \\
\hline No. of parents at home & 0.134 & 0.75 & 0.082 & 0.42 & 0.532 & 1.20 \\
\hline Head is male & 0.033 & 0.31 & -0.037 & -0.31 & 0.468 & 1.29 \\
\hline Age of head & -0.015 & -4.00 & -0.012 & -2.65 & -0.018 & -1.48 \\
\hline Head's education (years) & -0.002 & -0.34 & -0.002 & -0.26 & -0.014 & -0.62 \\
\hline Head worked in agriculture & -0.067 & -0.54 & 0.060 & 0.41 & -0.279 & -0.97 \\
\hline Head worked in industry & 0.078 & 1.05 & 0.084 & 1.03 & 0.114 & 0.53 \\
\hline Head worked in public sector & 0.053 & 0.68 & 0.080 & 0.95 & 0.011 & 0.05 \\
\hline Home is owned & -0.241 & -3.67 & -0.242 & -3.37 & -0.240 & -1.66 \\
\hline Resident in North West & -0.311 & -3.65 & -0.305 & -3.29 & -0.478 & -2.14 \\
\hline Resident in North East & -0.387 & -4.19 & 0.317 & -3.25 & -0.841 & -2.82 \\
\hline Resident in Centre & -0.204 & -2.53 & -0.168 & -1.92 & -0.553 & -2.54 \\
\hline Constant & -1.28 & -4.83 & -1.315 & -4.41 & -1.343 & -1.40 \\
\hline No. of observations & \multicolumn{2}{|c|}{6744} & \multicolumn{2}{|c|}{4633} & \multicolumn{2}{|c|}{2111} \\
\hline
\end{tabular}

Note: The reference categories are Head worked in service sector and Resident in South. Coefficients simultaneously computed with those in Table 3 by maximum likelihood method

a The coefficients are multiplied by 100

i. household income, net asset holdings, a dummy for having received assets in the past, and the liquidity ratio;

ii. the number of children and parents of the household head, and of the head's wife, differentiated by age group, and by whether they live in or out of the household;

iii. other personal characteristics of the household head (sex, age, education, sector of activity).

Table 3 shows that in the full sample credit rationing has a significantly positive effect on the probability of giving money. Other things being equal, an increase of $1 \%$ in the probability of being rationed raises the probability of making a transfer by $0.17 \% .{ }^{23}$ Credit rationing also has a significantly positive effect in the sub-sample of households with a head who did not retire yet. This effect is slightly larger than in the full sample (a $1 \%$ increase in the probability of being rationed increases the probability of making a transfer by $0.18 \%$ ). By

\footnotetext{
${ }^{23}$ This is the estimate, in percentage form (the so-called marginal effect), of the coefficient on credit rationing reported in Table 3.
} 
Table 3 Maximum likelihood estimation of the probability of making a transfer

\begin{tabular}{|c|c|c|c|c|c|c|}
\hline \multirow[t]{2}{*}{ Variable } & \multicolumn{2}{|c|}{$\begin{array}{l}\text { All households } \\
\text { with children }\end{array}$} & \multicolumn{2}{|c|}{ Head working } & \multicolumn{2}{|c|}{ Head retired } \\
\hline & Coeff & $t$-stat & Coeff & $t$-stat & Coeff & $t$-stat \\
\hline Credit is rationed & 1.370 & 3.69 & 1.612 & 3.81 & 1.36 & 1.60 \\
\hline Liquidity ratio & -0.003 & -5.61 & -0.003 & -4.23 & -0.004 & -4.01 \\
\hline Income $(\times 100)$ & 0.684 & 6.03 & 0.614 & 4.79 & 0.962 & 3.64 \\
\hline Assets $(\times 100)$ & 0.041 & 5.56 & 0.041 & 4.94 & 0.039 & 2.39 \\
\hline Received assets & 0.113 & 2.53 & 0.075 & 1.40 & 0.205 & 2.56 \\
\hline No. of children at home & -0.049 & -2.33 & -0.031 & -1.26 & -0.111 & -2.50 \\
\hline No. of children $\leq 30$ away & 0.111 & 3.44 & 0.123 & 3.02 & 0.102 & 1.79 \\
\hline No. of children $>30$ away & 0.035 & 1.62 & 0.071 & 2.05 & 0.012 & 0.42 \\
\hline No. of parents $\leq 60$ away & 0.032 & 0.53 & 0.019 & 0.30 & - & - \\
\hline No. of parents > 60 away & 0.009 & 0.28 & 0.003 & 0.08 & 0.037 & 0.39 \\
\hline No. of parents at home & 0.078 & 0.62 & 0.089 & 0.62 & -0.009 & -0.03 \\
\hline Head is male & 0.096 & 1.61 & 0.203 & 2.38 & -0.012 & -0.13 \\
\hline Age of head & 0.004 & 1.82 & 0.004 & 1.19 & 0.056 & 1.11 \\
\hline Head's education (years) & 0.027 & 5.16 & 0.029 & 4.79 & 0.020 & 1.96 \\
\hline Head worked in agriculture & -0.161 & -2.13 & -0.185 & -1.62 & -0.107 & -0.89 \\
\hline Head worked in industry & -0.158 & -3.25 & -0.163 & -2.80 & -0.143 & -1.44 \\
\hline Head worked in public sector & 0.023 & 0.47 & -0.043 & -0.73 & 0.165 & 1.65 \\
\hline Constant & -1.616 & -9.47 & -1.70 & -7.97 & -1.615 & -4.14 \\
\hline$\rho$ & -0.466 & -2.99 & -0.575 & -3.28 & -0.442 & -1.36 \\
\hline No. of observations & \multicolumn{2}{|c|}{6744} & \multicolumn{2}{|c|}{4633} & \multicolumn{2}{|c|}{2111} \\
\hline Log likelihood & \multicolumn{2}{|c|}{-3912.86} & \multicolumn{2}{|c|}{-2864.37} & \multicolumn{2}{|c|}{-1030.54} \\
\hline
\end{tabular}

Note: See note in Table 2

contrast, the probability of being rationed has no significant effect in the subsample of households with head already retired. These findings appear to reject the null hypothesis that self-enforcing family constitutions do not exist.

In the full sample, and in both sub-samples, the liquidity ratio has a negative effect on the probability of giving money. This disposes of two possible alternatives to the family constitution interpretation of our finding that creditrationed individuals are more likely to make monetary transfers. One is that a credit-rationed individual amassing cash with a view to buying a durable might use this temporary liquidity to make short-term loans to his children. Another is that a person intent on buying a home might have put together what she thinks is enough money for a down-payment before applying for a mortgage. If the mortgage is turned down, that person might then use the cash she has accumulated to make presents or loans to her children. If either of these alternatives were true, we should find that the more liquid the agent's portfolio, the higher the probability that the agent will make a transfer. However, we find the opposite.

Our explanation for why the first alternative does not work is that a person intent on buying a durable will not make loans that might be repaid too late, or not at all. If there is a family constitution, that will in fact guarantee only very long-term (20-30 year) implicit loans that will be repaid predominantly 
in the form of personal services. If no such constitution exists, there is no guarantee that the money will come back in any form. The reason why the second alternative does not work either is, in our opinion, that the banks use fixed rules for granting a mortgage. ${ }^{24}$ As these rules are well known to everyone concerned, it is unlikely that anybody will make mistakes and consequently be disappointed.

In the full sample, and in both sub-samples, income and assets have a significantly positive, but extremely small, effect on the probability of giving money. An explanation consistent with the constitution story is that, for a complier, making transfers is an obligation. Go-it-aloners, by contrast, have no reason to make transfers. The finding that the probability of making a transfer shows little sensitivity to small variations in the agent's economic circumstances could thus be explained by saying that income and asset changes affect transfer behavior only if they induce the agent to switch strategies. In other words, only marginal agents will change their transfer behavior. Having received assets in the past (by inheritance, or otherwise) also increases the probability of making a money transfer, but this effect is significant only in the sub-sample of households with a retired head. This leads to a number of possible interpretations, including that the old may give money for altruistic reasons or that altruism is genetically inherited.

In the full sample, and in the sub-sample of households with working head, the probability that someone in the household will give money to a non-coresident "friend or relative" is significantly and positively affected by the number of children aged up to 30 who live out of the parental home (in the sub-sample, also by the number of children aged more than 30 who live out). By contrast, that probability is negatively affected by the number of children living in (but the effect is significant only in the full sample). The parents of the household head, and of the head's partner, living either in or out of the household, have no significant effect on the probability of giving money. From this we infer that money transfers go essentially to the children of the household's head, or of the head's partner, and that this is true not only of transfers between households, but also of transfers within households (unrecorded in the survey). This does not necessarily mean that elderly parents get nothing. It may in fact mean that transfers to the old are essentially in the form of personal services. All the theories considered (altruism, exchange, constitution with or without altruism) do in fact predict that personal services will go primarily to the relatively rich, and money primarily to the relatively poor. In view of the fact that, in Italy as in other continental European countries, a generous public pension system makes the old relatively well provided with cash, all these theories then lead us to expect that money transfers will go mostly to the young, and personal services mostly to the old. Figures 3 and 4, constructed with data from ISTAT's

${ }^{24}$ Essentially, that the amount borrowed must not be more that a certain fraction of the market value of the house, and that the monthly repayment must not be higher than a certain fraction of the borrower's monthly income. 
Multiscopo, confirm that this is the case. That was indeed the motive for showing them.

In the sub-sample of households with retired heads, the number of children aged more than 30 living out of the parental home and the number of parents of either the household's head or the head's partner living either in or out of the household have no significant effect on the probability that someone in the household will make a money transfer to a non-coresident "friend or relative". The number of children living in affects the probability of making a transfer negatively. The number of children under age 30 who live out raises it slightly. The fact that some retired persons make money transfers is compatible with any of the theories under consideration, but there are also local reasons. The first is that the Italian tend to enter the labor market rather late, and in some cases do not become economically independent until the age of 30 . The second is that, at the time of the survey, retirement pensions were very generous in comparison with the earnings of current workers. It is thus possible that some recently retired household heads, or their partners, were still making transfers to their children in order to secure their support at a later stage.

The probability of making a money transfer increases with the household head's age and level of education. In the first sub-sample, this probability is significantly higher if the head is male. Households with a head employed in agriculture or in the industrial sector are less likely to make money transfers than households with head employed in the private service sector (the reference group). These effects are not significant in the second sub-sample. Working or having worked in the public sector has no significant effect on the probability of giving money in either the whole sample or the first sub-sample, but it has a negative and slightly significant effect in the second sub-sample. These effects have no obvious interpretation, but those relating to the sector of activity confirm that the populations represented by the two sub-samples are indeed different.

Finally, Table 3 reports the estimates of the coefficient $\rho$, which measures the correlation between the disturbances in the two equations (in other words, between the two sets of omitted factors) and may thus be regarded as a test of endogeneity for the rationing variable (Wooldridge, 2003, ch.15). For the full sample and for the first sub-sample, the estimates of $\rho$ turn out to be negative and significant, indicating that the unobservables of the two equations are negatively correlated. This implies that failing to account for endogeneity would result in an underestimate of the effect of credit rationing on the probability of giving money because the probit estimates would then be a convolution of a positive causal effect and a negative correlation between unobservables. In the second sub-sample, by contrast, we cannot reject the null hypothesis that the correlation coefficient is zero. This suggests that the probit estimation carried out without correcting for endogeneity provides a consistent estimate of the effect of being rationed. The finding that this 
effect is statistically insignificant does not reject the family constitution hypothesis. ${ }^{25}$

Since the information about access to credit could refer to any household member, the rationed person could in principle be a coresident adult rather than the household head or the head's partner. For our purposes, it is thus important to know whether the effect of the ration remains positive if we rule out the possibility that rationing might apply to some of the couple's grown-up children or elderly parents living in. We thus experimented with restricting the relevant sub-sample (the one with heads working) to households where there are neither children over the age of 18, nor parents of either the household head or the head's partner living in. The results, reported in Table 4, show that the effect of credit rationing is still positive and significant. ${ }^{26}$ The constitutional interpretation is thus applicable.

\section{Discussion}

Our aim was to ascertain whether voluntary money transfers could be explained by the existence of family constitutions prescribing the minimum level at which a middle-age person must support her young children and elderly parents. The hypothesis that such a person might find it advantageous to first acquiesce to such a constitution and then optimize subject to it was tested against the alternative usually assumed in the economic literature, namely that behavior is the outcome of individual optimization on the part of either altruistic or exchange motivated agents constrained only by the law of the land. Our research strategy was to identify a circumstance in which an agent could be expected to behave differently according to whether his actions were or were not constrained by a family constitution.

The circumstance is the presence of a binding credit ration, which raises the probability of making a money transfer if the agent has the option of

\footnotetext{
${ }^{25}$ As we are using several instruments for one endogenous variable, we performed an overidentification test (using the "overid" command implemented in STATA) as if the variables "transfer made" and "rationed" were continuous. In the full sample and in the sub-sample with a head still working, the hypothesis of orthogonality between the instruments and the error is only weakly accepted while in the sub-sample of households with a retired head the null of valid instruments is strongly not rejected (at the $1 \%$ level). That seems to throw doubt on our choice of instruments where the full sample and the first sub-sample are concerned. However, the overidentification test in question is designed for continuous variables, and it is thus not applicable to dichotomous variables like "transfer made" and "rationed". Furthermore, since the correlation between the error terms of the two equations is negative, ignoring the endogeneity of the probability of being rationed, leads to an underestimate of the effect of rationing on the probability of making a money transfer. The probit estimates obtained treating the "rationed" variable as exogenous may thus be regarded as lower bounds. As these lower bounds are positive in the case of households with head not retired, and zero in that of household with head retired, the null hypothesis that self-enforcing family constitutions do not exist would then be rejected even if the estimates obtained by the instrumental variables method were not valid.

${ }^{26}$ For the sake of brevity, the first stage results for the probability of being rationed are omitted from Table 4, but are available on request from the authors.
} 
Table 4 Maximum likelihood estimation of the probability of making a transfer for households consisting only of parents and children under 18 , both living in

\begin{tabular}{lcr}
\hline Variable & Coeff & $t$-stat \\
\hline Credit is rationed & 2.38 & 8.50 \\
Liquidity ratio & -0.002 & -2.36 \\
Income $(\times 100)$ & 1.055 & 4.87 \\
Assets $(\times 100)$ & 0.045 & 3.58 \\
Received assets & 0.146 & 2.09 \\
No. of children $\leq 18$ at home & 0.025 & 0.69 \\
No. of children $\leq 30$ away & 0.201 & 3.29 \\
No. of children > 30 away & 0.062 & 1.28 \\
No. of parents $\leq 60$ away & 0.054 & 0.80 \\
No. of parents $>60$ away & 0.032 & 0.74 \\
Head is male & -0.026 & -0.22 \\
Age of head & 0.003 & 0.69 \\
Head's education (years) & 0.008 & 1.03 \\
Head worked in agriculture & -0.328 & -2.85 \\
Head worked in industry & -0.491 & -4.32 \\
Head worked in public sector & -0.063 & -0.86 \\
Constant & -1.576 & -5.42 \\
$\rho$ & -0.9028 & 10.34 \\
No. of observations & \multicolumn{2}{c}{2747} \\
Log likelihood & -1693.605 \\
\hline
\end{tabular}

complying with a family constitution and reduces it otherwise. Allowing for the possibility that the credit ration is endogenous and that agents complying with a family constitution are more likely to be effectively rationed than agents doing the opposite, we find that rationing has a significantly positive effect on the probability of making a transfer if the agent is still working, but not if the agent is retired. This rejects the null hypothesis that the observed transfer behavior is the outcome of unfettered individual optimization. The opposite hypothesis cannot be rejected.

In a context like the Italian one, where a generous public pension system leaves (or, at least, left at the time of the survey) the old comparatively well provided with money, all the explanations of transfer behavior that we have examined imply that middle-age people transfer money primarily to the young and give personal services primarily to the old. The latter could not be verified on the Bank of Italy data used for our tests, because that survey is silent on the subject of personal services, but the almost contemporaneous Multiscopo, to which we refer for descriptive purposes (not for actual testing, because it does not provide information on rationing), and similar surveys relating to other countries, show that money transfers do indeed go prevalently to the young and personal services prevalently to the old. Assuming that money substitutes for the services of one's own grown-up children at a diminishing marginal rate, the money equivalent of the utility that the old derive from these services may be substantial.

As predicted by the family constitution model, we also find that the probability of making a voluntary money transfer shows little sensitivity to the giver's income and assets. This is consistent with evidence reported in Cox and Jakubson (1995), that redistributive policy is not fully offset by countervailing 
changes in private transfer behavior. In contrast with the alternative models considered, the constitution model predicts also that an increase in the share of the population compulsorily covered by an actuarially fair pension system would reduce aggregate fertility and possibly raise aggregate household saving. That could not be verified on our data, but evidence to that effect is found by Cigno and Rosati (1992, 1996, 1997), and Cigno et al. (2003), in time-series concerning a number of developed countries. This coincidence of micro and macro evidence lends credibility to the hypothesis that, even in developed market economies, a number of persons large enough to be statistically relevant does indeed comply with a family constitution.

Acknowledgments This paper originates from a suggestion by Donald Cox, and has benefitted from comments by Sonia Bhalotra. Constructive criticism by three anonymous referees helped to greatly improve the paper. Responsibility for remaining errors rests with the authors.

\section{References}

Altonji, J. G., Hayashi, F., \& Kotlikoff, L. J. (1995). Parental altruism and inter vivos transfers: Theory and evidence. Journal of Political Economy, 105, 1121-1166.

Altonji, J. G., Hayashi, F., \& Kotlikoff, L. J. (2000). The effects of income and wealth on time and money transfers between parents and children. In A. Mason \& G. Tapinos (Eds.), Sharing the wealth: Intergenerational economic relations and demographic change. New York and Oxford: Oxford University Press.

Attias-Donfut, C., \& Wolff, F. C. (2000). The redistributive effect of generational transfers. In S. Arber, \& C. Attias-Donfut (Eds.), The myth of generational conflict. The family and the state in ageing societies. London: Routledge.

Becker, G. S. (1974). A theory of social interactions. Journal of Political Economy, 82, 1063-1093.

Bhaumik, S. M., \& Nugent, J. B. (2000). Wealth accumulation, fertility, and transfers to to elderly households heads in Peru. In A. Mason, \& G. Tapinos (Eds.), Sharing the wealth: Intergenerational economic relations and demographic change. New York and Oxford: Oxford University Press.

Bound, J., Jaeger, D. A., \& Baker, R. M. (1995). Problems with instrumental variables estimation when the correlation between the instruments and endogenous explanatory variables is weak. Journal of the American Statistical Association, 90, 443-450.

Buchanan, J. (1987). Constitutional economics. In The new palgrave: A dictionary of economics. London: MacMillan.

Cigno, A. (1993). Intergenerational transfers without altruism: Family, market and state. European Journal of Political Economy, 7, 505-518.

Cigno, A. (2006). A constitutional theory of the family. Journal of Population Economics, 19, 259283.

Cigno, A., Casolaro, L., \& Rosati, F. C. (2003). The impact of social security on saving and fertility in Germany. FinanzArchiv, 59, 189-211.

Cigno, A., \& Rosati, F. C. (1992). The effects of financial markets and social security on saving and fertility behaviour in Italy. Journal of Population Economics, 5, 319-341.

Cigno, A., \& Rosati, F. C. (1996). Jointly determined saving and fertility behaviour: Theory, and estimates for Germany, Italy, UK, and USA. European Economic Review, 40, 1561-1589.

Cigno, A., \& Rosati, F. C. (1997). Rise and fall of the Japanese saving rate: The role of social security and intra-family transfers. Japan and the World Economy, 9, 81-92.

Cigno, A., \& Rosati, F. C. (2000). Mutual interest, self-enforcing constitutions and apparent generosity. In L. A. Gérard-Varet, S. C. Kolm, \& J. M. Ythier (Eds.), The economics of reciprocity, giving and altruism. London and New York: MacMillan and St Martin's Press.

Cox, D. (1987). Motives for private income transfers. Journal of Political Economy, 95, 508-546. 
Cox, D., \& Jakubson, G. (1995). The connection between public transfers and private interfamily transfers. Journal of Public Economics, 57, 129-167.

Cox, D., \& Rank, M. (1992). Inter-vivos transfers and intergenerational exchange. Review of Economics and Statistics, 74, 305-314.

Finch, J. (1989). Family obligations and social change. Oxford: Polity Press.

Foster, A. D., \& Rosenzweig, M. R. (2000). Financial intermediation, transfers, and commitment: Do banks crowd out private insurance arrangements in low-income rural areas? In A. Mason, \& G. Tapinos (Eds.), Sharing the wealth: Intergenerational economic relations and demographic change. New York and Oxford: Oxford University Press.

Greenwood, D. T., \& Wolff, E. N. (1992). Changes in wealth in the United States, 1962-83. Journal of Population Economics, 5, 261-288.

Guttman, J. M. (2001). Self-enforcing reciprocity norms and intergenerational transfers: Theory and evidence. Journal of Public Economics, 81, 117-151.

ISTAT (1993). Sintesi dei risultati dell'indagine. Indagine Multiscopo sulle Famiglie. Roma: Istituto Nazionale di Statistica

Rosati, F. C. (1996). Social security in a non-altruistic model with uncertainty and endogenous fertility. Journal of Public Economics, 60, 283-294.

Sloan, F. A., \& Zhang, H. H. (2002). Upstream intergenerational transfers. Southern Economic Journal, 69, 363-80.

Stark, O. (1995). Altruism and beyond. Cambridge: Cambridge University Press.

Wooldridge, J. (2003). Econometric analysis of cross section and panel data. Cambridge, MA: MIT Press. 